\author{
Mychailo BIDNIAK ${ }^{1}$ \\ Iryna MATEICHYK ${ }^{2}$
}

\title{
ПОСТРОЕНИЕ МОДЕЛИ СИСТЕМЫ ЭКОЛОГИЧЕСКОГО МЕНЕДЖМЕНТА ПРЕДПРИЯТИЯ
}

\footnotetext{
На основе системного подхода построена модель системы экологического менеджмента предприятия, в которой описаны состава и структура системы, отображены связи между компонентами.
}

\section{1. ВВЕДЕНИЕ}

Стратегической целью развития должно быть превращение природноресурсного потенциала в основу экономического роста, что соответствует верному пониманию сущности устойчивого развития с позиции мирового сообщества. В связи с этим экологический менеджмент следует рассматривать как качественно новую систему управления природопользованием в условиях рыночных отношений, с помощью которой, реформируя существующую модель согласно принципам устойчивого развития, можно достичь значительных экономических и социальных результатов как на макро-, так и на микроуровне [1].

Создание действенной системы экологического менеджмента (СЭМ) в условиях преодоления экологических проблем путем проведения институциональных и структурных реформ превращается в реальную необходимость и возможно только на основе методологии общей теории систем. Применение системного анализа для исследования СЭМ посредством представления ее в качестве системы, проведения структуризации и последующего анализа позволит упорядочить последовательность действий при решении проблемы обеспечения устойчивого состояния окружающей среды при осуществлении предприятием определенной хозяйственной деятельности. Системный анализ позволяет предприятию находить решения того класса проблем, который находится вне короткого диапазона ежедневной деятельности.

\section{2. ПРЕДПОСЫЛКИ ПОСТРОЕНИЯ МОДЕЛИ СИСТЕМЫ ЭКОЛОГИЧЕСКОГО МЕНЕДЖМЕНТА ПРЕДПРИЯТИЯ}

Эколого-экономические цели, которые ставит перед собой предприятие, чаще всего не могут быть достигнуты только за счет собственных возможностей или внешних средств, имеющихся у него в наличии в настоящий момент. В этом случае возникает проблемная ситуация, требующая системного подхода. Примером такой

\footnotetext{
${ }^{1}$ Prof., dr hab. Mychailo Bidniak, Katedra Zarządzania Narodowego Uniwersytetu Transportu w Kijowie, Ukraina.

${ }^{2}$ Mgr Iryna Mateichyk, Katedra Zarządzania Narodowego Uniwersytetu Transportu w Kijowie, Ukraina.
} 
ситуации для предприятия является случай, когда обычные способы снижения уровня воздействия предприятия на окружающую среду не обеспечивают выполнение как существующих нормативно-правовых требований, так и международных норм качества окружающей среды во время производственной деятельности, что существенно снижает экономическую стабильность предприятия.

В результате внедрения СЭМ предприятие берет на себя обязательства о соблюдении требований природоохранного законодательства, стандартов экологической безопасности и рационального природопользования, является движущей силой для завоевания конкурентных преимуществ как на внутреннем, так и на международном рынках. Также внедрение системы позволяет уменьшить простои вследствие тщательного мониторинга и технического обслуживания; перерабатывать отходы в коммерчески значимую форму; уменьшить энергопотребление; уменьшить расходы, связанные с утилизацией отходов. Внедрение СЭМ дает ряд преимуществ не только в улучшении экологических показателей предприятия, она приводит к улучшению морального климата в коллективе и повышение мотивации сотрудников.

Таким образом, внедрение на предприятии системы экологического менеджмента должно стать инструментом достижения цели обеспечения устойчивого состояния окружающей среды при осуществлении предприятием определенной хозяйственной деятельности.

Определив назначение системы $S=(A, R)$, для более точной характеристики ее конструкции, множества элементов $A$ и множества отношений $R$, следует развивать модель так, чтобы в результате получить ее более удобную форму, включая в нее, по мере необходимости, дополнительные сведения [2].

Системный поход к построению модели СЭМ на предприятии предполагает построение и развитие ряда моделей.

\section{3. ПОСТРОЕНИЕ МОДЕЛИ СИСТЕМЫ ЭКОЛОГИЧЕСКОГО МЕНЕДЖМЕНТА ПРЕДПРИЯТИЯ}

Представим СЭМ в виде непрозрачного “ящика”, выделенного из окружающей среды. Подчеркнем, что уже эта, максимально простая, модель по-своему отражает два следующих важных свойства системы: целостность и обособленность от среды.

Достигнутая цель представляет собой запланированные заранее изменения в окружающей среде, какие-то продукты работы системы, предназначенные для потребления вне ее. Иначе говоря, система связана со средой и с помощью этих связей, которые называются выходами системы, и воздействуют на среду. Кроме того, система является средством, поэтому должны существовать и возможности ее использования, воздействия на нее, т.п. Связи со средой, которые направлены извне в систему, служат входами системы.

Выделим в СЭМ предприятия в качестве входов те элементы системы, которые предназначены для обеспечения устойчивого состояния окружающей среды при осуществлении предприятием определенной хозяйственной деятельности. Входами системной модели, которая описывает СЭМ предприятия, целесообразно выбрать такие управляющие параметры, как нормативно-правовые требования к обеспечению экологической безопасности предприятия; экономические 
инструменты, регулирующие деятельность предприятия, в том числе связанную с природоиспользованием и природоохранной деятельностью; экологические показатели работы предприятия; организационная структура предприятия; техникотехнологические параметры, обеспечивающие хозяйственную деятельность предприятия. Выходными параметрами являются показатели изменения состояния окружающей среды - количество выбросов вредных веществ в атмосферу, количество образованных и не утилизированных отходов, количество загрязнений грунтов вследствие вытекания масел и т.д. Изменение этих показателей в свою очередь, за счет обратной связи, будут влиять на входные параметры модели. Особенностью системной модели СЭМ является свойство постоянного улучшения, основанное на принципе Деминга-Шухарта (модель PDCA) и спиралевидный характер жизненного цикла СЭМ [3].

Модель СЭМ в виде “черного ящика" не описывает характеристики, элементы, связи и процессы внутреннего устройства системы. Для этого необходимы более развитые, более детальные модели - модель состава системы и модель структуры системы.

Рассмотрим подходы к построению модели состава системы. При рассмотрении любой системы прежде всего обнаруживается то, что ее целостность и обособленность (отображенные в модели черного ящика) выступают как внешние свойства. Внутренность же “ящика” оказывается неоднородной, что позволяет различать составные части самой системы. При более детальном рассмотрении некоторые части системы могут быть, в свою очередь, разбиты на составные части и т.д.

Модель состава системы отображает, из каких частей (подсистем и элементов) состоит система. Модель состава системы СЭМ включает такие подсистемы, как подсистема подготовки к внедрению СЭМ; подсистема планирования; подсистема управления; подсистема выполнения работ; подсистема контроля; подсистема выполнения соответствующих управляющих воздействий. Каждая из выделенных подсистем имеет свою иерархию внутренних подсистем и элементов. Следует заметить, что входные и выходные параметры тоже можно представить подсистемами, состоящими из конечного множества элементов. Упрощенная модель состава системы СЭМ приведена в табл. 1.

Модель состава системы СЭМ можно представить как

$$
\text { Mss: } X_{i}=\left[X_{i, j}, j=\{1, N\}\right] \stackrel{P_{1} P U D C A}{\longrightarrow} Y_{i}=\left[Y_{i, j}, j=\{1, N\}\right]
$$

где $M s s$ - модель состава системы СЭМ, $X_{i}$ - подсистема входных параметров, $Y_{i}$ - подсистема выходных параметров,

$P_{1} P U D C A$ - механизм внедрения системы экологического менеджмента, позволяющий перевести систему из состояния $X_{i}$ в состояние $\mathrm{Y}_{\mathrm{i}}$. 
Таблица 1. Упрощенная модель состава системы СЭМ

\begin{tabular}{|c|c|c|}
\hline $\begin{array}{l}\text { Подсисте } \\
\text { ма }\end{array}$ & Состав & Элементы \\
\hline \multirow{5}{*}{ 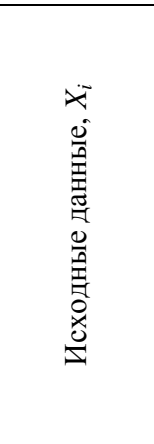 } & $\begin{array}{l}\text { Правовые требования } \quad \text { к } \\
\text { обеспечению } \quad \text { экологической } \\
\text { безопасности предприятия }\end{array}$ & $\begin{array}{l}\text { Законы Украины, Постановления правительства, } \\
\text { Распоряжения органов местного самоуправ- } \\
\text { ления, приказы по предприятию }\end{array}$ \\
\hline & $\begin{array}{l}\text { Экономические показатели } \\
\text { деятельности предприятия }\end{array}$ & $\begin{array}{ll}\text { Финансово-экономические } & \text { показатели } \\
\text { деятельности предприятия } & \\
\end{array}$ \\
\hline & Экологические показатели & $\begin{array}{lccc}\text { Количество } & \text { выбросов } & \text { в } & \text { атмосферу, } \\
\text { количество отходов, количество сливов }\end{array}$ \\
\hline & $\begin{array}{l}\text { Организационная структура } \\
\text { предприятия }\end{array}$ & $\begin{array}{lcr}\text { Структура } & \text { предприятия, } \\
\text { работников, } & \text { количество } \\
\text { персонала, уровень квалификации } & \text { управляющего }\end{array}$ \\
\hline & $\begin{array}{l}\text { Технико-технологические } \\
\text { параметры }\end{array}$ & $\begin{array}{l}\text { Состояние и количество оборудования, } \\
\text { используемые технологии, }\end{array}$ \\
\hline \multirow{3}{*}{ 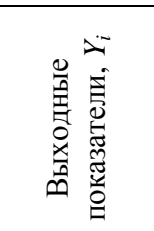 } & Экологические показатели & $\begin{array}{l}\text { Уменьшение количества выбросов в атмосферу, } \\
\text { количества отходов, количества сливов }\end{array}$ \\
\hline & Экономические показатели & $\begin{array}{lc}\text { Улучшение } & \text { финансово-экономических } \\
\text { показателей деятельности предприятия }\end{array}$ \\
\hline & Организационные & $\begin{array}{lcc}\text { Улучшенная } & \text { структура } & \text { предприятия, } \\
\text { количество обученных сотрудников }\end{array}$ \\
\hline \multirow{3}{*}{  } & $\begin{array}{l}\text { Принятие решения } \\
\text { внедрении СЭМ }\end{array}$ & $\begin{array}{l}\text { Назначение ответственных по предприятию. } \\
\text { Определение сроков внедрения СЭМ, уровня } \\
\text { результатов. Приказ о внедрении СЭМ. }\end{array}$ \\
\hline & $\begin{array}{l}\text { Определение ответственных в } \\
\text { структурных подразделениях }\end{array}$ & $\begin{array}{l}\text { Реестр экологических аспектов, } \\
\text { нормативно-правовых документов. }\end{array}$ \\
\hline & $\begin{array}{l}\text { Проведение } \\
\text { экологического анализа }\end{array}$ & $\begin{array}{l}\text { Порядок проведения и результаты анализа. } \\
\text { Определение порядка работ. }\end{array}$ \\
\hline \multirow{2}{*}{  } & $\begin{array}{l}\text { Разработка экологической } \\
\text { политики предприятия }\end{array}$ & $\begin{array}{lcc}\text { Экологическая } & \text { политика } & \text { предприятия, } \\
\text { заверенная руководителем предприятия }\end{array}$ \\
\hline & $\begin{array}{l}\text { Разработка экологических } \\
\text { целей, задач, программа }\end{array}$ & $\begin{array}{l}\text { Программа внедрения системы экологического } \\
\text { менеджмента, заверенная руководителем }\end{array}$ \\
\hline \multirow{3}{*}{ 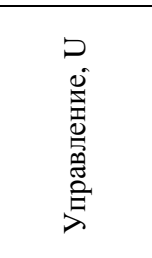 } & $\begin{array}{l}\text { Разработка Руководства СЭМ } \\
\text { на основе стандарта ISO } \\
14001\end{array}$ & $\begin{array}{l}\text { Руководство СЭМ, заверенное руководителем } \\
\text { предприятия }\end{array}$ \\
\hline & $\begin{array}{l}\text { Разработка } \quad \text { отдельных } \\
\text { процессов и процедур СЭМ }\end{array}$ & Процедуры процессов СЭМ \\
\hline & $\begin{array}{l}\text { Разработка документации III- } \\
\text { IV уровня }\end{array}$ & Инструкции, инструктажи, журналы работ \\
\hline \multirow{2}{*}{  } & $\begin{array}{l}\text { Работы } \quad \text { по } \\
\text { качества окружающей средын }\end{array}$ & $\begin{array}{lcc}\text { Изменение } & \text { технологических } & \text { процессов, } \\
\text { внедрение нового оборудования } & \end{array}$ \\
\hline & Организационные работы & $\begin{array}{l}\text { Изменение структуры предприятия, обучение } \\
\text { персонала }\end{array}$ \\
\hline \multirow{3}{*}{$\begin{array}{l}u \\
\hat{0} \\
0 \\
0 \\
0 \\
0 \\
0\end{array}$} & $\begin{array}{l}\text { Проведение } \\
\text { аудита }\end{array}$ & \multirow[t]{3}{*}{$\begin{array}{l}\text { Документация (протокол аудита, листки } \\
\text { несоответствия), аудиторы, результаты }\end{array}$} \\
\hline & $\begin{array}{l}\text { Проведение } \\
\text { сертификационного аудита }\end{array}$ & \\
\hline & $\begin{array}{l}\text { Проведение } \\
\text { аудита }\end{array}$ & \\
\hline
\end{tabular}


Главная трудность в построении модели состава заключается в том, что разделение целостной системы на части является относительным, условным, зависящим от целей моделирования (это относится не только к границам между частями системы, но и к границам самой системы). Кроме того, относительным является и определение самой малой части - элемента.

Модель структуры системы отображает связи между компонентами модели ее состава, т.е. совокупность связанных между собой моделей “черного ящика” для каждой из частей системы. Поэтому трудности построения модели структуры те же, что и для построения модели “черного ящика”. Связи между компонентами модели могут отражаться материальным, энергетическим и информационным потоком. При построении модели системы экологического менеджмента материальный поток будем оценивать потоком денежной массы (экономическими показателями), энергетический поток - снижением эмиссий в окружающую среду (экологический показатель), а информационный поток оценит эффективность управления СЭМ.

Обобщенная системная модель системы экологического менеджмента предприятия приведена на рис. 1. Представленная модель включает элементы обобщенной модели в виде “черного ящика", модели состава системы СЭМ с определенными подсистемами, модели структуры системы с отображением связи между подсистемами и модели РDCA, основанной на принципе постоянного улучшения в течение всего жизненного цикла работы модели.

Модель охватывает пять главных фаз процесса управления, имеет циклический характер:

а) анализ проблемы и ее решения: изучение и подробное определение проблемы; рассмотрение различных вариантов решений (подсистема Анализ ресурсов);

б) планирование общей политики и программы: определение главных задач программы и подготовка плана программы (подсистема Планирование);

в) планирование управления: определение путей, методов и особенностей реализации программы (подсистема Управление);

г) реализация программы: обеспечение товаров и (или) услуг в управляемых условиях (подсистема Выполнение);

д) мониторинг и контроль: проверка эффективности подготовки и организации ресурсов, необходимых для реализации программы и обеспечения ее эффективности (подсистемы Контроль и Коррекция). 


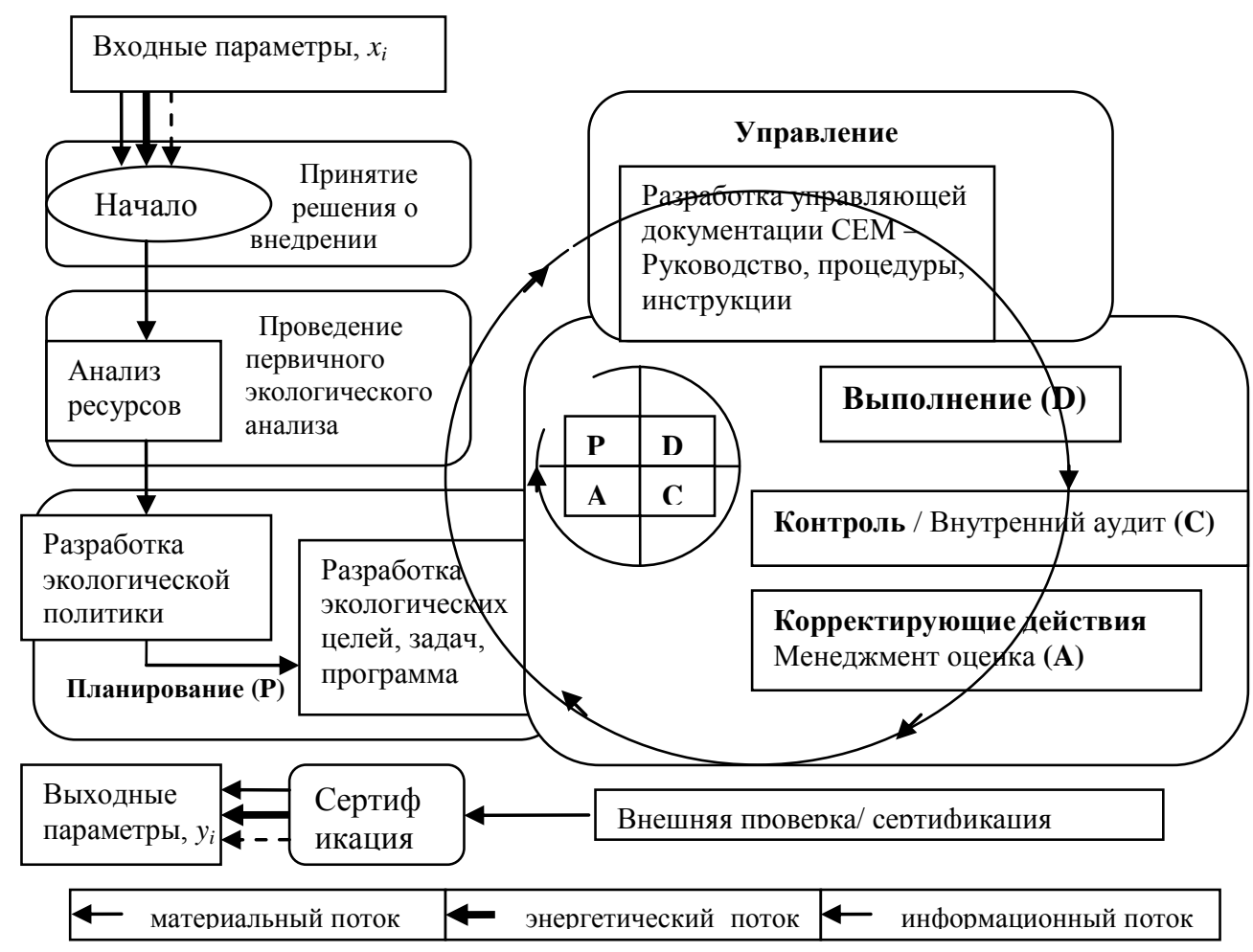

Рис.1. Модель системы экологического менеджмента предприятия

При внедрении модели различные этапы этого процесса перекрывают друг друга, так что каждый начинается прежде, чем завершается предыдущий. Значение такого перекрытия заключается в том, что оно способствует непрерывности работы и позволяет поддерживать поток информации между последовательными этапами. Кроме взаимодействий, изображенных стрелками, существует также множество обратных связей и возможно циклическое возвращение от более поздних к более ранним этапам.

Для эффективной организации в системе экологического менеджмента движения материальных потоков ресурсов, энергетических потоков влияния на окружающую среду и информационных потоков требуемых знаний, умений и навыков необходимо учитывать внешние ограничения, которые влияют на все компоненты системы. Внутренние ограничения системы определяются еe состоянием и способствуют или мешают проведению изменений и влияют на процесс управления. Примерами внутренних ограничений является наличие или отсутствие информации, на которой должен основываться анализ, ее качество, количество и качество персонала, задействованного для реализации программы, положительное или отрицательное отношение к изменениям, привычные методы работы, наличие организационных структур и другие факторы, связанные с устойчивым состоянием системы. 


\section{4. ВЫводЫ}

Основной целью внедрения на предприятии системы экологического менеджмента является обеспечение устойчивого состояния окружающей среды при осуществлении предприятием определенной хозяйственной деятельности. Для определения путей достижения этой цели разработано ряд моделей. Наиболее общая модель, это модель СЭМ в виде “черного ящика", которая позволила определить внешние воздействия на систему, входные и выходные параметры. Модель состава системы СЭМ включает подсистемы и их элементы. Модель структуры системы отображает связи между компонентами модели. Интеграция разработанных моделей с моделью PDCA позволила построить модель системы экологического менеджмента.

Разработанная модель позволяет проанализировать последовательность действий при внедрении системы экологического менеджмента предприятия, что, в свою очередь, будет способствовать решению проблемы обеспечения устойчивого состояния окружающей среды при осуществлении предприятием определенной хозяйственной деятельности.

\section{ЛИТЕРАТУРА}

[1] Екологічний менеджмент: навчальний посібник // За ред. М.Ф.Дмитриченка, Вид. НТУ, Київ 2010, 250 с.

[2] Ф. И. Перегудов, Ф. П.Тарасенко, Введение в системный анализ, Изд. „Высшая школа”, Москва 1989, 360 с.

[3] Белмане И., Далхаммар К., Системы экологического менеджмента: от теории к практике. Руководство по внедрению СЭМ в соответствии с требованиями Международного Стандарта ИСО 14001, Изд. МИИЭЭ Лундского Университета, 2000, 197 с.

\section{CONSTRUCTION OF ENVIRONMENTAL MANAGEMENT SYSTEM MODEL OF ENTERPRISE}

On the basis of the systems approach the environmental management system model of an enterprise is built, in which there were described the composition and structure of the system, as well as there were presented the connections between the elements.

DOI: $10.7862 /$ rz.2012.zim.14 